\title{
Penggunaan Fraud Pentagon dalam Mendeteksi Kecurangan Laporan Keuangan Perusahaan Perbankan di Indonesia
}

\author{
Ni Nyoman Ayu Nirmala Putra1 \\ Herkulanus Bambang Suprasto ${ }^{2}$ \\ 1,2Fakultas Ekonomi dan Bsnis Universitas Udayana, Indonesia \\ ${ }^{*}$ Correspondences: omangomang220@yahoo.com
}

\begin{abstract}
ABSTRAK
Kecurangan laporan keuangan merupakan kecurangan yang proporsinya rendah dibandingkan dengan korupsi dan penyalahgunaan asset. Namun, dampak kerugian yang diakibatkan justru yang paling besar. Penelitian ini bertujuan untuk menguji penerapan fraud pentagon dalam mendeteksi kecurangan laporan keuangan. Pengujian dilakukan pada perusahaan perbankan yang terdaftar di bursa efek Indonesia selama periode 2016-2019 dengan sampel sebanyak 34 perusahaan yang dipilih melalui metode purposive sampling. Analisis data dalam penelitian ini menggunakan analisis regresi linear berganda. Hasil penelitian menunjukkan stabilitas keuangan dan pengawasan yang tidak efektif meningkatkan risiko terjadinya kecurangan laporan keuangan. Sedangkan, target keuangan, pergantian auditor, pergantian direksi dan jumlah foto CEO tidak berpengaruh pada terjadinya kecurangan laporan keuangan. Penelitian ini juga membuktikan bahwa tekanan eksternal dapat mengurangi risiko terjadinya kecurangan laporan keuangan.
\end{abstract}

Kata Kunci: Fraud Pentagon; Kecurangan Laporan Keuangan; Perusahaan Perbankan.

The Use of Pentagon Fraud in Detecting Fraudulent Financial Statements of Banking Companies in Indonesia

\begin{abstract}
Compared to corruption and asset misappropriation, fraudulent financial reporting is a minor form of fraud. The impact of the resulting losses, on the other hand, is the most severe. The purpose of this research is to look into the use of the fraud pentagon in detecting fraudulent financial statements. During the 2016-2019 period, testing was conducted on banking companies listed on the Indonesian stock exchange, with a sample of 34 companies chosen using the purposive sampling method. Multiple linear regression analysis was used to analyze the data in this study. Financial stability and ineffective supervision, according to the findings, increased the risk of financial statement fraud. Meanwhile, financial targets, external pressure, auditor turnover, director changes, and the number of CEO photos had no impact on the occurrence of fraudulent financial statements. This research also proves that external pressure can reduce risk of financial statement fraud.

Keywords: Fraud Pentagon; Fraudulent Financial Reporting; Banking Companies.
\end{abstract}

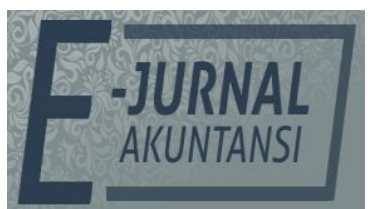

e-ISSN 2302-8556

Vol. 32 No. 1

Denpasar, Januari 2021

Hal. 168-182

DOI:

10.24843/EJA.2021.v32.i01.p12

PENGUTIPAN:

Putra, N. N. A. N. \&

Suprasto, H. B. (2022).

Penggunaan Fraud Pentagon dalam Mendeteksi

Kecurangan Laporan

Keuangan Perusahaan

Perbankan di Indonesia. E-

Jurnal Akuntansi, 32(1), 168-182

RIWAYAT ARTIKEL: Artikel Masuk: 29 April 2021 Artikel Diterima: 9 Juli 2021

Artikel dapat diakses : https://ojs.unud.ac.id/index.php/Akuntansi/index 


\section{PENDAHULUAN}

Laporan keuangan merupakan cerminan dari kondisi suatu perusahaan karena dalam laporan tersebut terdapat berbagai macam informasi keuangan yang dibutuhkan oleh berbagai pihak yang berkepentingan. Oleh karena itu, informasi yang terkandung dalam laporan keuangan harus menggambarkan proses akuntansi yang terdapat dalam perusahaan secara keseluruhan dan memenuhi karakteristik kualitatif dari informasi keuangan, yaitu relevansi, dapat diandalkan, kelengkapan, ketepatan waktu, dapat dimengerti, dapat diverifikasi dan dapat diakses (Hidayah \& Saptarini, 2019). Perusahaan dalam menyusun laporan keuangan selalu berusaha menunjukkan kinerja terbaiknya agar mendapat kesan dan penilaian yang baik dari berbagai pihak yang berkepentingan, ini bisa menjadi motivasi utama manajemen untuk melakukan berbagai manipulasi di bagian tertentu (Hidayah \& Saptarini, 2019). Manipulasi laporan keuangan adalah tindakan penipuan yang dapat merugikan berbagai pemangku kepentingan (Septriyani \& Handayani, 2018). Hasil survei Association of Certified Fraud Examiners (ACFE) yang berjudul Report to The Nation 2020 Global Study on Occupational Fraud and Abuse Asia Pasific Edition menyatakan kecurangan laporan keuangan merupakan kecurangan yang rendah proporsinya dibandingkan dengan jenis kecurangan lainnya, seperti korupsi dan penyalahgunaan aset, namun dampak kerugian yang diakibatkan justru merupakan yang terbesar. Kerugian tersebut dapat terjadi karena pelaku manipulasi laporan keuangan didominasi oleh pihak internal perusahaan yakni manajer atau pihak yang memiliki wewenang lebih di dalam perusahaan, sehingga mempermudah mereka untuk melakukan tindakan kecurangan (D Ariyanto et al., 2020 dan Suparmini et al., 2020). Pada tahun 2018 terkuak kasus pembobolan kredit 14 bank dengan nilai kerugian mencapai Rp 14 triliun oleh SNP Finance. Bank Mandiri menjadi salah satu bank yang memberikan fasilitas kredit kepada anak perusahaan Grup Colombia tersebut. Pemberian kredit oleh Bank Mandiri didasarkan kepada laporan keuangan dari salah satu kantor akuntan publik ternama, yaitu Deloitte. Namun ternyata terjadi pemalsuan data dan manipulasi laporan keuangan yang dilakukan oleh manajemen SNP Finance, diantaranya adalah membuat piutang fiktif melalui penjualan fiktif. Pada tahun yang sama, PT Bank Bukopin Tbk melakukan revisi laporan keuangan tiga tahun terakhir, yaitu 2015, 2016, dan 2017. Revisi laporan keuangan tersebut dilakukan karena terdapat kesalahan penyajian pada piutang kartu kredit bank yang disebabkan oleh modifikasi kartu kredit tertentu serta kesalahan penyajian pada pembiayaan/piutang syariah. Akibatnya berdampak pada menurunnya laba bersih serta meningkatnya beban perusahaan sehingga sangat merugikan berbagai pihak dalam pengambilan keputusan, terutama pihak investor (Ratnasari \& Solikhah, 2019).

Penelitian yang dilakukan oleh Tessa (2016) pada perusahaan perbankan menerapkan fraud pentagon theory dalam beberapa variabel yang terdiri dari target keuangan, stabilitas keuangan, tekanan eksternal, kepemilikian institusional, pengawasan yang tidak efektif, kualitas auditor eksternal, pergantian auditor, pergantian direksi dan frekuensi kemunculan gambar CEO memberikan hasil bahwa terdapat tiga variabel yang berpengaruh secara signifikan terhadap kecurangan laporan keuangan, antara lain target keuangan, tekanan eksternal, dan 
jumlah foto CEO pada laporan keuangan perusahaan. Penelitian dengan model yang sama dilakukan oleh Ulfah et al. (2017) menggunakan beberapa variabel, yaitu target keuangan, stabilitas keuangan, tekanan eksternal, kepemilikan saham institusi, ketidakefektifan pengawasan, pergantian auditor, opini auditor, kualitas auditor eksternal, pergantian direksi, dan frekuensi kemunculan gambar CEO. Hasil penelitian menunjukkan bahwa hanya variabel pergantian auditor dan opini auditor yang berpengaruh signifikan terhadap kecurangan laporan keuangan.

Teori keagenan menjelaskan hubungan antara pemegang saham (shareholders) sebagai prinsipal dan manajemen sebagai agen dalam suatu kontrak kerjasama. Agen secara moral bertanggung jawab untuk mengoptimalkan keuntungan para pemilik (principal), namun di sisi lain manajer juga mempunyai kepentingan memaksimumkan kesejahteraan mereka. Conflict of interest atau perbedaan kepentingan antara prinsipal dan agen inilah yang dapat memicu agency problem dimana pihak agen akan berupaya untuk memaksimalkan kepentingan dirinya sendiri sementara mengabaikan kepentingan prinsipal padahal tujuan utama dari suatu perusahaan adalah untuk memaksimalkan kesejahteraan pemilik modal. Pada kondisi ini, agen memiliki informasi yang lebih banyak dibandingkan principal. Ketidakseimbangan informasi antara principal dan agen disebut disebut asimetri informasi. Adanya asimetri informasi di antara kedua belah pihak dapat memberikan kesempatan kepada agen untuk menyembunyikan beberapa informasi yang tidak diketahui oleh prinsipal. Kecurangan laporan keuangan dapat terjadi karena adanya celah atau peluang yang secara sengaja dimanfaatkan oleh agen tanpa diketahui oleh principal. Selain itu, adanya tekanan dari principal yang menuntut agar agen menjalankan kegiatan operasional perusahaan dengan baik dan dapat mencapai target sesuai yang diinginkan. Keadaan ini dapat menimbulkan tekanan bagi agen sehingga mendorongnya untuk melakukan tindak kecurangan. Penelitian sebelumnya mengenai fraud masih didominasi oleh model fraud diamond dan fraud triangle (Saria et al., 2019). Model yang ada harus diperbarui untuk beradaptasi dengan perkembangan terkini di lapangan dengan insiden penipuan yang terus berkembang.

Teori agensi menjelaskan bahwa manajer adalah pihak yang dikontrak oleh prinsipal untuk bekerja demi kepentingannya. Manajer diharapkan memberikan kinerja yang optimal untuk memenuhi keinginan prinsipal, salah satunya pengelolaan aset dengan baik. Pengelolan aset bertujuan untuk meningkatkan bonus dan menghasilkan pengembalian yang tinggi untuk para investornya. Tujuan ini kadang disalah artikan, manajemen akan memanfaatkan laporan keuangan sebagai alat untuk menutupi kondisi stabilitas perusahaan. Manajer menghadapi tekanan untuk melakukan kecurangan laporan keuangan ketika stabilitas keuangan atau profitabilitas terancam oleh kondisi ekonomi, industri, atau operasi entitas (SAS No. 99 dalam Skousen et al. (2009)). Hasil analisis ini sejalan dengan penelitian yang dilakukan oleh Lestari \& Henny (2019), Ratnasari \& Solikhah (2019), dan Tessa (2016) menunjukkan bahwa stabilitas keuangan berpengaruh positif pada kecurangan laporan keuangan.

$\mathrm{H}_{1}$ : Stabilitas keuangan berpengaruh positif pada kecurangan laporan keuangan.

Teori keagenan menjelaskan bahwa antara principal dan agen memiliki kepentingan yang berbeda (Jensen \& Meckling, 1976). Principal menginginkan 
return yang tinggi atas investasinya sementara agen memiliki kepentingan untuk mendapatkan bonus atas hasil kinerja mereka. Bonus tersebut didapat jika pemenuhan keinginan principal berupa target keuangan dapat tercapai. Target keuangan dalam penelitian ini diukur dengan return on asset (ROA). ROA yang tinggi pada tahun sebelumnya akan menjadi tuntunan bagi manajemen agar tetap mempertahankan profitabilitas tersebut, sehingga motivasi untuk melakukan kecurangan semakin tinggi (Mardianto \& Tiono, 2019). Semakin tinggi target ROA perusahaan maka semakin rentan manajemen akan manipulasi laba yang menjadi salah satu bentuk penipuan (Sunardi \& Amin, 2018). Hasil analisis ini sejalan dengan penelitian yang dilakukan oleh (Akbar, 2017), (Husmawati et al., 2017), dan (Widarti, 2015) menunjukkan bahwa target keuangan berpengaruh positif pada kecurangan laporan keuangan.

$\mathrm{H}_{2}$ : Target keuangan berpengaruh positif pada kecurangan laporan keuangan.

Teori keagenan menjelaskan kedudukan manajer sebagai agen yang dilimpahkan wewenang oleh principal untuk menjalankan perusahaan. Oleh karena itu, manajemen bertanggungjawab untuk mengoptimalkan keuntungan dan memajukan perusahaan. Tekanan eksternal dalam penelitian ini diukur dengan rasio leverage yaitu perbandingan antara total kewajiban dengan total aset. Menurut Tessa (2016), jika perusahaan memiliki leverage yang tinggi maka perusahaan dianggap mempunyai hutang yang besar dan risiko kredit yang dimilikinya juga tinggi. Semakin tinggi risiko kredit maka tingkat kekhawatiran kreditor juga tinggi dalam memberikan pinjaman kepada perusahaan. Tekanan tersebut dapat mendorong manajemen untuk melakukan kecurangan agar tetap dipandang baik oleh principal. Hasil analisis ini sejalan dengan penelitian yang dilakukan oleh Akbar (2017), Indarto \& Ghozali (2016), Septriyani \& Handayani, (2018), Tessa (2016), dan Zaki (2017) menunjukkan bahwa tekanan eksternal berpengaruh positif kecurangan laporan keuangan.

Teori keagenan menjelaskan kedudukan manajer sebagai agen yang dilimpahkan wewenang oleh principal untuk menjalankan perusahaan. Oleh karena itu, manajemen bertanggungjawab untuk mengoptimalkan keuntungan dan memajukan perusahaan. Tekanan eksternal dalam penelitian ini diukur dengan rasio leverage yaitu perbandingan antara total kewajiban dengan total aset. Menurut Tessa (2016), jika perusahaan memiliki leverage yang tinggi maka perusahaan dianggap mempunyai hutang yang besar dan risiko kredit yang dimilikinya juga tinggi. Semakin tinggi risiko kredit maka tingkat kekhawatiran kreditor juga tinggi dalam memberikan pinjaman kepada perusahaan. Tekanan tersebut dapat mendorong manajemen untuk melakukan kecurangan agar tetap dipandang baik oleh principal. Hasil analisis ini sejalan dengan penelitian yang dilakukan oleh Akbar (2017), Indarto \& Ghozali (2016), Septriyani \& Handayani, (2018), Tessa (2016), Zaki (2017) menunjukkan bahwa tekanan eksternal berpengaruh positif kecurangan laporan keuangan.

$\mathrm{H}_{3}$ : Tekanan eksternal berpengaruh positif pada kecurangan laporan keuangan.

Hubungan keagenan merupakan suatu kontrak antara principal (pemegang saham) dengan agen (manajer) untuk melakukan suatu jasa atas nama prinsipal dan memberi wewenang kepada agen untuk membuat keputusan yang terbaik bagi prinsipal. Hal tersebut menyebabkan manajer mengetahui informasi internal lebih banyak mengenai perusahaan dibandingkan dengan prinsipal. Informasi 
yang disampaikan oleh manajer terkadang tidak sesuai dengan kondisi perusahaan yang sebenarnya karena manajer cenderung untuk melaporkan sesuatu yang memaksimalkan keuntungannya. Maka dari itu diperlukan pengawasan internal yang kuat. Tanpa adanya pengawasan internal yang kuat sebagai media kontrol dalam suatu organisasi, maka kemungkinan terjadinya kecurangan semakin besar (ACFE Indonesia, 2019). Hasil analisis ini sejalan dengan penelitian yang dilakukan Agusputri \& Sofie (2019), Budiman \& Fadillah (2017), Faradiza (2019), Septriyani \& Handayani (2018) menunjukkan bahwa pengawasan yang tidak efektif berpengaruh positif pada kecurangan laporan keuangan.

Pergantian auditor yang digunakan perusahaan dapat dianggap sebagai suatu bentuk untuk menghilangkan jejak fraud (fraud trail) yang ditemukan oleh auditor sebelumnya (Sasongko \& Wijayantika, 2019). Kecenderungan tersebut mendorong perusahaan untuk mengganti auditor independennya guna menutupi kecurangan yang terdapat dalam perusahaan. Masa kerja jangka panjang auditor di suatu perusahaan akan mempengaruhi independensi (Ozcelik, 2020). Menurut SAS No. 99 menyatakan bahwa dengan adanya pergantian auditor di dalam perusahaan dapat diindikasi adanya kecurangan (AICPA, 2002). Auditor yang lama mungkin mengetahui pendeteksian kemungkinan adanya kecurangan yang dilakukan oleh manajemen. Hasil analisis ini sejalan dengan penelitian yang dilakukan oleh Puspitha \& Yasa (2018), Saputra \& Kesumaningrum (2017), Ulfah et al. (2017) menunjukkan bahwa pergantian auditor berpengaruh positif pada kecurangan laporan keuangan.

$\mathrm{H}_{5}$ : Pergantian auditor berpengaruh positif pada kecurangan laporan keuangan.

Teori keagenan menjelaskan bahwa dewan direksi sebagai agen memiliki kepentingan pribadi untuk mensejahterakan dirinya sendiri, sehingga hal tersebut tidak sesuai dengan harapan prinsipal. Akibatnya, perusahaan melakukan pergantian direksi untuk mengurangi adanya konflik agensi antara agen dengan prinsipal. pergantian direksi dianggap dapat mengurangi efektivitas dalam kinerja karena memerlukan waktu yang lebih untuk beradaptasi dengan lingkungan direksi baru. Wolfe \& Hermanson (2004) menjelaskan bahwa pergantian direksi dapat menyebabkan stress period yang berdampak pada semakin terbukanya peluang untuk melakukan tindak kecurangan. Hasil analisis ini sejalan dengan penelitian yang dilakukan oleh Devy et al. (2017), Faradiza (2019), Sasongko \& Wijayantika (2019), (Dodik Ariyanto et al., 2021) menunjukkan bahwa pergantian direksi berpengaruh positif pada kecurangan laporan keuangan.

$\mathrm{H}_{6}$ : Pergantian direksi berpengaruh positif pada kecurangan laporan keuangan.

Banyaknya foto CEO dalam sebuah laporan tahunan perusahaan dapat merepresentasikan tingkat arogansi atau superioritas yang dimiliki CEO tersebut (Sasongko \& Wijayantika, 2019). Seorang CEO cenderung lebih ingin menunjukkan kepada semua orang akan status dan posisi yang dimilikinya dalam perusahaan karena mereka tidak ingin kehilangan status atau posisi tersebut (atau merasa tidak dianggap). Tingkat arogansi yang tinggi dapat menimbulkan terjadinya fraud karena dengan arogansi dan superioritas yang dimiliki seorang CEO, membuat CEO merasa bahwa segala peraturan dan pengendalian internal apapun tidak akan berlaku bagi dirinya karena status dan posisi yang dimiliki. 
Menurut Marks (2012), terdapat kemungkinan bahwa CEO akan melakukan cara apapun untuk mempertahankan posisi dan kedudukan yang sekarang dimiliki. Hasil analisis ini sejalan dengan penelitian yang dilakukan oleh Lestari \& Henny (2019), Puspitha \& Yasa (2018), Sari \& Nugroho, (2020), Tessa (2016) menunjukkan bahwa jumlah foto CEO berpengaruh positif pada kecurangan laporan keuangan. $\mathrm{H}_{7}$ : Jumlah foto $\mathrm{CEO}$ berpengaruh positif pada kecurangan laporan keuangan.

\section{METODE PENELITIAN}

Penelitian ini menggunakan pendekatan kuantitatif yang terbentuk asosiatif, yaitu suatu penelitian yang bertujuan untuk mengetahui hubungan yang bersifat sebab akibat (kausal) antara variabel independen dan variabel dependen (Sugiyono, 2019). Penelitian ini menggunakan sumber data sekunder berupa laporan keuangan perusahaan perbankan yang terdaftar atau listing di Bursa Efek Indonesia yang diperoleh dengan mengakses website resmi www.idx.co.id dan sumber- sumber literatur lainnya yang dapat digunakan. Populasi dalam penelitian ini adalah seluruh perusahaan perbankan yang terdaftar di Bursa Efek Indonesia periode 2017-2019 sebanyak 42 perusahaan.

Variabel dependen $(\mathrm{Y})$ dalam penelitian ini adalah kecurangan laporan keuangan yang diukur dengan F-Score model yang dikembangkan oleh Dechow et al. (2012). Perhitungan F-Score model diperoleh dari jumlah dua komponen, yaitu kualitas akrual dan kinerja keuangan yang dapat dilihat dalam laporan keuangan Skousen \& Twedt (2009), dapat dirumuskan dengan persamaan berikut:

F-Score = Accrual Quality + Financial Performance

Accrual quality dapat diproksikan dengan RSST accrual dan variabel financial performance dengan melihat perubahan dalam akun piutang, perubahan dalam akun penjualan tunai dan perubahan pada pendapatan sebelum bunga dan pajak (Richardson et al., 2005).

$\mathrm{WC}=($ Current Assets - Current Liability $)$

$$
\text { RSST Accrual }=\frac{\Delta \mathrm{WC}+\Delta \mathrm{NCO}+\Delta \mathrm{FIN}}{\text { Average Total Assets }}
$$

$\mathrm{NCO}=($ Total Assets - Current Assets - Investment and Advances $)-($ Total

Liabilities - Current Liabilities - Long Term Debt)

FIN $=$ (Total Investment - Total Liabilities)

Average total assets $=($ Beginning Total Assets + End Total Assets $) / 2$

Financial performance $=$ change in receivable + change in inventories + change

in cash sales + change in earnings.....

Change in receivables $=\frac{\Delta \text { Receivables }}{\text { Average Total Assets }}$.

Change in inventories $=\frac{\Delta \text { Inventories }}{\text { Average Total Assets }}$

Change in cash sales $=\frac{\Delta \text { Sales }}{\text { Sales }(\mathrm{t})}-\frac{\Delta \text { Receivables }}{\text { Receivables }(\mathrm{t})}$

Change in earnings $=\frac{\text { Earnings }(\mathrm{t})}{\text { Average Total Assets }(\mathrm{t})}-\frac{\text { Earnings }(\mathrm{t}-1)}{\text { Average Total Assets }(\mathrm{t}-1)}$

Variabel independen $\left(X_{1}\right)$ dalam penelitian ini adalah stabilitas keuangan. Penelitian yang dilakukan Skousen et al. (2009) menggunakan rasio perubahan total asset sebagai alat ukur stabilitas keuangan. Rasio perubahan total aset (ACHANGE) dapat dihitung dengan rumus berikut. 


$$
\text { ACHANGE }=\frac{\text { Totat Aset }(\mathrm{t})-\text { Total Aset }(\mathrm{t}-1)}{\text { Total Aset }(\mathrm{t}-1)}
$$

Variabel independen $\left(\mathrm{X}_{2}\right)$ dalam penelitian ini adalah target keuangan. Return on asset (ROA) merupakan rasio profitabilitas yang digunakan untuk mengukur kinerja perusahaan (Skousen et al., 2009). ROA dapat dihitung dengan rumus sebagai berikut:

$$
\text { ROA }=\frac{\text { Laba Sebelum Pajak }}{\text { Total Aset }}
$$

Variabel indepen $\left(\mathrm{X}_{3}\right)$ dalam penelitian ini adalah tekanan eksternal. Salah satu sumber tekanan eksternal dapat berasal dari kemampuan perusahaan membayar utang dan memenuhi perjanjian utang (Skousen et al., 2009). Tekanan eksternal diukur dengan rasio leverage (LEV). Rasio leverage dihitung dengan rumus (Skousen et al., 2009).

$$
\mathrm{LEV}=\frac{\text { Total Kewajiban }}{\text { Total Aset }}
$$

Variabel independen $\left(\mathrm{X}_{4}\right)$ dalam penelitian ini adalah pengawasan yang tidak efektif. Pengawasan yang tidak efektif diukur menggunakan perbandingan antara jumlah komisaris independen dengan jumlah total dewan komisaris.

$$
\text { BDOUT }=\frac{\text { Jumlah Dewan Komisaris Independen }}{\text { Jumlah Total Dewan Komisaris }}
$$

Variabel independen $\left(\mathrm{X}_{5}\right)$ dalam penelitian ini adalah pergantian auditor. Pergantian kantor akuntan publik ( $\triangle \mathrm{CPA}$ ) yang diukur dengan variabel dummy dimana apabila terdapat perubahan Kantor Akuntan Publik selama periode 20172019 maka diberi kode 1, sebaliknya apabila tidak terdapat perubahan kantor akuntan publik diberi kode 0 .

Variabel independen $\left(\mathrm{X}_{6}\right)$ dalam penelitian ini adalah pergantian direksi. Pergantian direksi diukur dengan variabel dummy, kode 1 jika terdapat pergantian direksi dalam perusahaan, kode 0 jika tidak terdapat pergantian direksi di dalam perusahaan.

Variabel independen $\left(X_{7}\right)$ dalam penelitian ini adalah jumlah foto CEO dalam laporan tahunan perusahaan. Banyaknya foto $\mathrm{CEO}$ yang terpampang dalam sebuah laporan tahunan perusahaan dapat merepresentasikan tingkat arogansi atau superioritas yang dimiliki CEO tersebut. Jumlah foto CEO dalam laporan tahunan perusahaan diukur dengan total foto CEO yang terpampang dalam sebuah laporan tahunan.

Adapun teknik analisis yang digunakan dalam penelitian adalah analisis regresi linear berganda dengan persamaan sebagai berikut.

F-SCORE $=a+\beta_{1} X_{1}+\beta_{2} X_{2}+\beta_{3} X_{3}+\beta_{4} X_{4}+\beta_{5} X_{5}+\beta_{6} X_{6}+\beta_{7} X_{7}+\beta_{8} X_{8}+\varepsilon$

Keterangan:

$$
\begin{array}{ll}
\text { F-score } & =\text { Kecurangan laporan keuangan } \\
\mathrm{a} & =\text { Konstanta } \\
\beta_{1}, \beta_{2}, \beta_{\mathrm{dst}} & =\text { Koefisien regresi dari variabel independen } \\
\mathrm{X}_{1} & =\text { Rasio perubahan total aset } \\
\mathrm{X}_{2} & =\text { Return on asset } \\
\mathrm{X}_{3} & =\text { Rasio leverage } \\
\mathrm{X}_{4} & =\text { Rasio jumlah komisaris independen dengan total komisaris } \\
\mathrm{X}_{5} & =\text { Pergantian auditor } \\
\mathrm{X}_{6} & =\text { Pergantian direksi } \\
\mathrm{X}_{7} & =\text { Jumlah foto CEO dalam laporan tahunan }
\end{array}
$$




\section{HASIL DAN PEMBAHASAN}

Deskripsi data dari masing-masing variabel penelitian ini akan menyajikan data tentang nilai terkecil (minimum), nilai terbesar (maximum), nilai rata-rata (mean) dan nilai simpangan baku (Standard Deviation). Deskripsi data setiap variabel penelitian tersaji pada Tabel 1 .

\section{Tabel 1. Hasil Analisis Statistik Deskriptif}

\begin{tabular}{lcccc}
\hline Variables & Minimum & Maximum & Mean & Std. Deviation \\
\hline ACHANGE & $-0,180$ & 1,145 & 0,115 & 0,157 \\
ROA & $-0,107$ & 0,040 & 0,010 & 0,020 \\
LEVERAGE & 0,052 & 0,936 & 0,793 & 0,160 \\
BDOUT & 0,400 & 1,000 & 0,583 & 0,110 \\
AUD CHANGE & 0,000 & 1,000 & 0,227 & 0,421 \\
DIRECTOR CHANGE & 0,000 & 1,000 & 0,522 & 0,501 \\
TOTAL CEO PIC & 1,000 & 5,000 & 2,764 & 0,669 \\
F-SCORE & $-0,976$ & 1,168 & $-0,522$ & 0,335 \\
\hline
\end{tabular}

Sumber: Data Penelitian, 2021

Berdasarkan hasil analisis statistik deskriptif, nilai terkecil F-Score adalah sebesar $-0,976$ dan terbesar 1,168. Nilai rata-rata yang didapat adalah sebesar 0,522 dengan nilai simpangan baku sebesar 0,335. Nilai terkecil ACHANGE adalah sebesar -0,180 dan terbesar 1,145. Nilai rata-rata yang didapat adalah sebesar 0,115 dengan nilai simpangan baku sebesar 0,157. Nilai terkecil ROA adalah sebesar 0,107 dan terbesar 0,040. Nilai rata-rata yang didapat adalah sebesar 0,0108 dengan nilai simpangan baku sebesar 0,020. Nilai terkecil Leverage adalah sebesar 0,052 dan terbesar 0,936 . Nilai rata-rata yang didapat adalah sebesar 0,793 dengan nilai simpangan baku sebesar 0,160. Nilai terkecil BDOUT adalah sebesar 0,400 dan terbesar 1,000. Nilai rata-rata yang didapat adalah sebesar 0,583 dengan nilai simpangan baku sebesar 0,110. Nilai rata-rata perubahan auditor sebesar 0,227 dengan standar deviasi 0,421. Nilai rata-rata yang mendekati 0 menunjukkan 38 perusahaan perbankan cenderung tidak terdapat perubahan kantor akuntan publik. Nilai rata-rata pergantian direksi sebesar 0,522 dengan standar deviasi 0,501. Nilai rata-rata yang mendekati 1 menunjukkan 38 perusahaan perbankan cenderung melakukan pergantian direksi. Nilai terkecil TOTAL CEO PIC adalah sebesar 1 dan terbesar 5 . Nilai rata- rata yang didapat adalah sebesar 2,764 dengan nilai simpangan baku sebesar 0,669.

Sebelumnya, telah dilakukan uji asumsi klasik yaitu uji normalitas, uji multikolinearitas, uji autokorelasi dan uji heteroskedastisitas. Hasil uji normalitas menunjukkan nilai Test Statistic sebesar 0,071 dengan Asymp.Sig. sebesar 0,089. Nilai signifikansi lebih besar dari batas kesalahan $(\alpha=0,05)$ yang diterapkan dalam penelitian ini menunjukkan bahwa model uji telah memenuhi asumsi normalitas data. Hasil uji multikolinearitas menunjukkan bahwa nilai Tolerance pada seluruh variabel bebas sudah lebih besar dari 0,1 dengan nilai VIF lebih kecil dari 10. Jadi, dapat dinyatakan bahwa seluruh variabel bebas tidak memiliki korelasi satu dengan lainnya. Hasil tersebut menunjukkan bahwa model uji tidak ditemukan kasus multikolinearitas. Hasil uji autokorelasi menunjukkan nilai Durbin-Watson sebesar 2,127 berada di antara DU dan 4-DU atau disebut sebagai daerah bebas autokorelasi. Hasil uji heterokedastisitas menunjukkan tidak ada variabel bebas yang berpengaruh signifikan terhadap variabel terikatnya, Hal ini 
ditunjukkan dengan nilai signifikansi yang lebih besar dari 0,05. Jadi, dapat dinyatakan tidak ditemukan adanya perbedaan variance pada model uji.

Tabel 2. Hasil Regresi Linear Berganda

\begin{tabular}{lcrrrr}
\hline & $\begin{array}{c}\text { Expected } \\
\text { correlation }\end{array}$ & Coefficient & Std. Error & t-ratio & \multicolumn{1}{c}{$p$-value } \\
\hline const & $?$ & 0,895 & 0,063 & 14,271 & $0,000^{* * *}$ \\
ACHANGE & + & 0,377 & 0,052 & 7,314 & $0,000^{* * *}$ \\
ROA & + & $-0,632$ & 0,413 & $-1,530$ & 0,128 \\
LEVERAGE & + & $-1,914$ & 0,050 & $-37,965$ & $0,000^{* * *}$ \\
BDOUT & + & 0,168 & 0,073 & 2,306 & $0,023^{* *}$ \\
AUD CHANGE & & $-0,021$ & 0,019 & $-1,118$ & 0,266 \\
DIRECTOR & + & $-0,001$ & 0,016 & $-0,039$ & 0,969 \\
CHANGE & + & $-0,011$ & 0,012 & $-0,881$ & 0,380 \\
TOTAL CEO PIC & + & & & & 0,928 \\
Adjusted R square & & & & & 250,896 \\
F hitung & & & & & 0,000 \\
Sig F hitung & & & &
\end{tabular}

Sumber: Data Penelitian, 2021

Berdasarkan Tabel 2, model persamaan regresi linear berganda yang dihasilkan adalah sebagai berikut.

$\mathrm{Y}=0,895+0,377 \beta_{1}-0,632 \beta_{2}-1,914 \beta_{3}+0,168 \beta_{4}-0,021 \beta_{5}-0,001 \beta_{6}-0,011 \beta_{7}$

Uji kelayakan model dilakukan dengan melihat hasil uji F. Hasil uji

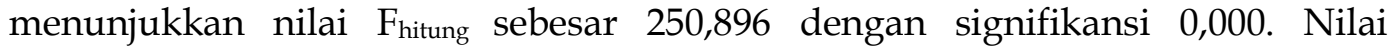
signifikansi yang lebih kecil dari batas kesalahan $(\alpha=0,05)$ ini menunjukkan bahwa model uji regresi yang digunakan dalam penelitian ini sudah layak digunakan untuk memprediksi pengaruh dari stabilitas keuangan, target keuangan, tekanan eksternal, pengawasan tidak efektif, pergantian auditor, pergantian direksi dan jumlah foto CEO terhadap kecurangan laporan keuangan. Uji determinasi digunakan untuk mengetahui total pengaruh dari seluruh variabel bebas terhadap variabel terikatnya. Koefisien determinasi pada penelitian ini adalah sebesar 0,288 . Jadi dapat dinyatakan bahwa total pengaruh dari stabilitas keuangan, target keuangan, tekanan eksternal, pengawasan tidak efektif, pergantian auditor, pergantian direksi dan jumlah foto CEO terhadap kecurangan laporan keuangan adalah sebesar 92,8 persen. Jadi sisa sebesar 8,2 persen dijelaskan oleh variabel bebas lainnya yang tidak digunakan dalam penelitian ini.

Uji hipotesis dalam penelitian ini menggunakan uji $t$ dengan melihat $\mathrm{p}$ value dari masing-masing uji $t$ untuk melihat adanya pengaruh yang signifikan. Koefisien regresi digunakan untuk melihat arah pengaruh sehingga dapat diketahui terpenuhi atau tidaknya hipotesis yang diajukan dalam penelitian ini. Hasil uji regresi variabel stabilitas keuangan menunjukkan koefisien regresi sebesar 0,377. Uji t menunjukkan koefisien sebesar 7,314 dengan signifikansi 0,000. Nilai signifikansi yang lebih kecil dari batas kesalahan yang ditetapkan dalam penelitian $(\alpha=0,05)$ ini menunjukkan bahwa hipotesis $\left(\mathrm{H}_{1}\right)$ diterima. Hasil penelitian ini mendukung teori agensi yang menyatakan bahwa kondisi keuangan perusahaan yang tidak stabil merupakan tekanan bagi pihak manajemen karena memiliki kinerja buruk dan menunjukkan ketidakmampuan manajemen dalam memaksimalkan aset yang dimilikinya (Puspitasari \& Hastuti, 2020). Kondisi keuangan yang tidak stabil mencerminkan tingginya risiko bisnis yang dihadapi 
perusahaan (Haqq \& Budiwitjaksono, 2020). Kondisi perusahaan yang tidak stabil terjadi karena manajemen tidak mampu mengelola aset yang dimiliki, sehingga menyebabkan perubahan total aset yang terlalu tinggi atau terlalu rendah selama periode tertentu. Kondisi keuangan yang stabil dapat memperkecil risiko terjadinya kecurangan. Hasil penelitian ini sejalan dengan penelitian yang dilakukan oleh Skousen et al. (2009) yang menyatakan bahwa semakin besar rasio perubahan total aset suatu perusahaan maka indikasi kecurangan laporan keuangan semakin tinggi. Hasil ini juga didukung oleh penelitian yang dilakukan oleh oleh Lestari \& Henny (2019), Ratnasari \& Solikhah (2019), Septriyani \& Handayani (2018) menyatakan bahwa stabilitas keuangan berpengaruh positif dan signifikan pada kecurangan laporan keuangan.

Hasil uji regresi menunjukkan koefisien regresi target keuangan sebesar 0,632 . Uji t menunjukkan koefisien sebesar $-1,530$ dengan signifikansi 0,128 . Nilai signifikansi yang lebih besar dari batas kesalahan yang ditetapkan dalam penelitian $(\alpha=0,05)$ menunjukkan bahwa hipotesis kedua tidak mampu dibuktikan. Nilai ROA perusahaan perbankan dipengaruhi oleh kondisi ekonomi yang dihadapi industri. ROA yang tinggi dikaitkan dengan kinerja operasi di atas rata-rata dan keputusan yang menjadi dasar proses intermediasi perbankan (Kupiec \& Lee, 2013). Banyak faktor eksternal maupun internal yang mempengaruhi kinerja bank. Faktor internal lebih berfokus pada kondisi setiap bank, sehingga berbeda antara satu bank dengan lainnya, seperti kebijakan hutang, kondisi likuiditas bank, dan ukuran bank. Selain faktor tersebut, kondisi makro juga mempengaruhi, seperti PDB (Produk Domestik Bruto) dan inflasi (Shaferi \& Handayani, 2017). Jadi, nilai ROA bukanlah sebuah tekanan untuk menilai kinerja manajemen karena banyak faktor yang mempengaruhinya. Hasil penelitian ini sejalan dengan penelitian yang dilakukan oleh Saputra \& Kesumaningrum (2017), Tessa (2016), Yulianti et al. (2019) yang menyatakan bahwa target keuangan tidak berpengaruh pada kecurangan laporan keuangan.

Koefisien regresi variabel tekanan eksternal sebesar -1,914. Uji $t$ menunjukkan koefisien sebesar $-37,965$ dengan signifikansi 0,000. Nilai signifikansi yang lebih kecil dari batas kesalahan yang ditetapkan dalam penelitian $(a=0,05)$ serta arah koefisien yang negatif menunjukkan bahwa hipotesis $\left(\mathrm{H}_{3}\right)$ tidak mampu dibuktikan. Semakin tinggi rasio total kewajiban terhadap total aset suatu perusahaan dapat menurunkan potensi kecurangan laporan keuangan. Hal ini karena rasio leverage perusahaan perbankan diatur dalam ketentuan POJK Nomor 11/POJK.03/2016 mengenai Kewajiban Penyediaan Modal Minimum Bank Umum (POJK KPMM), sehingga fleksibilitas manajemen untuk melakukan kecurangan laporan keuangan semakin berkurang. Hasil penelitian ini didukung dengan penelitian yang dilakukan Hidayah \& Saptarini (2019), Septriyani \& Handayani (2018), Situngkir \& Triyanto (2020) yang menyatakan tekanan eksternal dapat mengurangi potensi kecurangan laporan keuangan.

Hasil uji regresi variabel pengawasan yang tidak efektif menunjukkan koefisien regresi sebesar 0,168. Uji t menunjukkan koefisien sebesar 2,306 dengan signifikansi 0,023 . Nilai signifikansi yang lebih kecil dari batas kesalahan yang ditetapkan dalam penelitian $(\alpha=0,05)$ dan arah koefisien yang positif menunjukkan bahwa hipotesis (H4) diterima. Jumlah komisaris independen 
terhadap jumlah keseluruhan anggota dewan komisaris pada perusahaan perbankan relatif tetap selama tahun pengamatan dengan rata-rata 58,3\%. Proporsi dewan komisaris independen terhadap jumlah total dewan komisaris sudah lebih dari 50\%, hal ini menandakan komisaris independen dinilai kurang bekerja secara efektif dan maksimal dalam mengawasai manajemen, sehingga membuka peluang bagi manajemen untuk melakukan tindak kecurangan dalam menyusun laporan keuangan (Septriyani \& Handayani, 2018). Hasil penelitian ini sejalan penelitian yang dilakukan oleh Lestari \& Henny (2019), Puspitha \& Yasa (2018), Septriyani \& Handayani (2018) yang menyatakan bahwa pengawasan yang tidak efektif berpengaruh positif dan signifikan pada kecurangan laporan keuangan.

Hasil uji regresi variabel pergantian auditor menunjukkan koefisien regresi sebesar $-0,021$. Uji t menunjukkan koefisien sebesar -1,118 dengan signifikansi 0,266 . Nilai signifikansi yang lebih besar dari batas kesalahan yang ditetapkan dalam penelitian $(\alpha=0,05)$ menunjukkan bahwa hipotesis (H5) tidak mampu dibuktikan. Pergantian auditor bisa disebabkan karena perusahaan merasa tidak puas atas kinerja Kantor Akuntan Publik (KAP) pada periode sebelumnya. Pergantian auditor dilakukan untuk memperbaiki kinerja auditor eksternal pada periode sebelumnya dengan tujuan meningkatkan kualitas laporan keuangan perusahaan sehingga investor akan tertarik untuk berinvestasi pada perusahaan. Selain itu, perusahaan menaati mentaati Peraturan Pemerintah Nomor 20 Tahun 2015 tentang Praktik Akuntan Publik pasal 11 ayat 1 yang menyatakan bahwa pemberian jasa audit atas informasi keuangan historis terhadap suatu entitas oleh seorang Akuntan Publik dibatasi paling lama untuk 5 (lima) tahun buku berturutturut. Hasil penelitian ini sejalan dengan penelitian yang dilakukan oleh Bawakes et al. (2018), Sari \& Lestari (2020), Tessa (2016).

Hasil uji regresi variabel pergantian direksi menunjukkan koefisien regresi sebesar -0,001. Uji t menunjukkan koefisien sebesar -0,039 dengan signifikansi 0,969 . Nilai c dicantumkan guna memperkenalkan kepada masyarakat luas terutama para pemangku kepentingan siapa CEO perusahaan tersebut. Foto yang dicantumkan dalam laporan tahunan kebanyakan merupakan foto hasil kegiatan. Jumlah foto CEO juga bisa dikaitkan dengan hal-hal yang positif, yaitu kepercayaan diri. Kepercayaan diri dibangun atas dasar kesuksesan dan prestasi, kemampuan yang telah dikuasi, prinsip dan norma yang dipegang teguh serta kepedulian yang ditunjukkan kepada orang lain (Mukhtaruddin et al., 2020). Hasil penelitian ini sejalan dengan penelitian yang dilakukan oleh Lestari \& Henny (2019), Sasongko \& Wijayantika (2019), Siddiq et al. (2017).

\section{SIMPULAN}

Penelitian ini tidak dapat membuktikan sepenuhnya elemen dari fraud pentagon dalam mendeteksi adanya kecurangan laporan keuangan. Hasil penelitian dari tujuh hipotesis menunjukkan hanya variabel stabilitas keuangan dan pengawasan yang tidak efektif yang berpengaruh positif dan signifikan pada kecurangan laporan keuangan di perusahaan perbankan. Penelitian ini tidak dapat membuktikan target keuangan, tekanan eksternal, pergantian auditor, pergantian direksi dan jumlah foto CEO berpengaruh pada kecurangan laporan keuangan di perusahaan perbankan. 
Penelitian ini hanya terbatas pada perusahaan perbankan sehingga hasil penelitian tidak dapat digeneralisasi untuk seluruh perusahaan yang terdaftar di Bursa Efek Indonesia. Penelitian selanjutnya dapat memilih sampel penelitian dengan sektor industri yang beragam sehingga dapat menggambarkan dengan lebih baik fenomena kecurangan laporan keuangan menggunakan fraud pentagon.

\section{REFERENSI}

Agusputri, H., \& Sofie, S. (2019). Faktor - Faktor Yang Berpengaruh Terhadap Fraudulent Financial Reporting Dengan Menggunakan Analisis Fraud Pentagon. Jurnal Informasi, Perpajakan, Akuntansi, Dan Keuangan Publik, 14(2), 105. https://doi.org/10.25105/jipak.v14i2.5049

Akbar, T. (2017). the Determination of Fraudulent Financial Reporting Causes By Using Pentagon Theory on Manufacturing Companies in Indonesia. International Journal of Business, Economics and Law, 14(5), 106-113.

Ariyanto, D, Firdaus, G. M., Sari, M. M. R., Dewi, A. A., \& Jhuniantara, I. M. G. (2020). How self control and situational pressure influence the tendency to receive gratification: An experimental study. International Journal of Criminology and Sociology, 9, 400-414. https://doi.org/10.6000/19294409.2020.09.39

Ariyanto, Dodik, Jhuniantara, I. M. G., Ratnadi, N. M. D., Putri, I. G. A. M. A. D., \& Dewi, A. A. (2021). Detecting fraudulent financial statements in pharmaceutical companies: Fraud pentagon theory perspective. Accounting, 7(7), 1611-1620. https://doi.org/10.5267/j.ac.2021.5.009

Bawakes, H. F., Simanjuntak, A. M. ., \& Daat, S. C. (2018). Pengujian Teori Fraud Pentagon Terhadap Fraudulent Financial Reporting. Jurnal Akuntansi $\mathcal{E}$ Keuangan Daerah, 13(1), 114-134.

Budiman, A., \& Fadillah, A. R. (2017). Pengaruh rasio kredit macet dan likuiditas terhadap kinerja keuangan bank perkreditan rakyat. Jurnal Ekonomi Manajemen, 3(2), 120-128.

Dechow, P. M., Hutton, A. P., Kim, J. H., \& Sloan, R. G. (2012). Detecting Earnings Management: A New Approach. Journal of Accounting Research, 50(2), 275-334. https://doi.org/10.1111/j.1475-679X.2012.00449.x

Devy, K. L. S., Wahyuni, M. A., \& Sulindawati, N. L. G. E. (2017). Pengaruh Frequent Number of Ceos Picture, Pergantian Direksi Perusahaan Dan External Pressure Dalam Mendeteksi Fraudulent Financial Reporting (Studi Empiris Pada Perusahaan Farmasi Yang Listing Di Bei Periode 2012-2016). JIMAT (Jurnal Ilmiah Mahasiswa Akuntansi S1), 8(2). https:// doi.org/10.23887/jimat.v8i2.10392

Faradiza, S. A. (2019). Fraud Pentagon Dan Kecurangan Laporan Keuangan. EkBis: Jurnal Ekonomi Dan Bisnis, 2(1), 1-22. https://doi.org/10.14421/ekbis.2018.2.1.1060

Hanifa, S. I., \& Laksito, H. (2015). Pengaruh Fraud Indicators Terhadap Fraudulent Financial Statement: Studi Empiris Pada Perusahaan Yang Listed Di Bursa Efek Indonesia (BEI) TAHUN 2008-2013. Diponegoro Journal of Accounting, 4(4), 411-425.

Haqq, A. P. N. A., \& Budiwitjaksono, G. S. (2020). Fraud Pentagon for Detecting 
Financial Statement Fraud. Journal of Economics, Business, and Accountancy Ventura, 22(3), 319-332. https:// doi.org/10.14414/jebav.v22i3.1788

Hidayah, E., \& Saptarini, G. D. (2019). Pentagon Fraud Analysis in Detecting Potential Financial Statement Fraud of Banking Companies in Indonesia. International Conference on Acoounting, Business, E Economics, 2010, 89-102.

Husmawati, P., Septriani, Y., Rosita, I., \& Handayani, D. (2017). Fraud Pentagon Analysis in Assessing the Likelihood of Fraudulent Financial Statement (Study on Manufacturing Firms Listed in Bursa Efek Indonesia Period 20132016). International Conference of Applied Science on Engineering, Business, Linguistics and Information Technology (ICo-ASCNITech), October, 45-51.

Indarto, S. L., \& Ghozali, I. (2016). Fraud diamond: Detection analysis on the fraudulent financial reporting. Risk Governance and Control: Financial Markets and Institutions, 6(4), 116-123. https://doi.org/10.22495/rcgv6i4c1art1

Jensen, M. C., \& Meckling, W. H. (1976). Theory of the Firm: Managerial Behavior, Agency Costs And Ownership Structure. Journal of Financial Economics, 3(4), 305-360. https:/ / doi.org/ http:/ / dx.doi.org/10.1016/0304-405X(76)90026-X

Kupiec, P., \& Lee, Y. (2013). What factors explain differences in return on assets among community banks?

Kurnia, A. A., \& Anis, I. (2017). Analisis Fraud Pentagon Dalam Mendeteksi Kecurangan Laporan Keuangan dengan Menggunakan Fraud Score Model. Simposium Nasional Akuntansi XX, Jember.

Lestari, M. I., \& Henny, D. (2019). Pengaruh Fraud Pentagon Terhadap Fraudulent Financial Statements Pada Perusahaan Perbankan Yang Terdaftar Di Bursa Efek Indonesia Tahun 2015-2017. Jurnal Akuntansi Trisakti, 6(1). https://doi.org/10.25105/jat.v6i1.5274

Mardianto, M., \& Tiono, C. (2019). ANALISIS PENGARUH FRAUD TRIANGLE DALAM MENDETEKSI KECURANGAN LAPORAN KEUANGAN. Jurnal Benefita, 1(1), 41. https:/ / doi.org/10.22216/jbe.v1i1.3349

Marks, J. (2012). The Mind Behind The Fraudsters Crime: Key Behavioral and Environmental Elements. Crowe Horwath LLP, 1-62. www.crowe.com

Mukhtaruddin, Sabrina, E., Hakiki, A., Saftiana, Y., \& Kalsum, U. (2020). Fraudulent Financial Reporting: Fraud Pentagon Analysis in Banking and Financial Sector Companies. Issues in Business Management and Economics, 8(2), 12-24.

Puspitasari, G., \& Hastuti, A. W. (2020). Analisis Pengaruh Fraud Pentagon Untuk Mendeteksi Manipulasi Laporan Keuangan. Jurnal Akuntansi Dan Perpajakan, 6(1), 26-38. https:// doi.org/10.26905/ap.v6i1.4007

Puspitha, M. Y., \& Yasa, G. W. (2018). Fraud Pentagon Analysis in Detecting Fraudulent Financial Reporting (Study on Indonesian Capital Market). International Journal of Sciences: Basic and Applied Research, 42(5), 93-109.

Ratnasari, E., \& Solikhah, B. (2019). Analysis of Fraudulent Financial Statement: The Fraud Pentagon Theory Approach. Gorontalo Accounting Journal, 2(2), 98112.

Richardson, S. A., Sloan, R. G., Soliman, M. T., \& Tuna, I. (2005). Accrual reliability, earnings persistence and stock prices. Journal of Accounting and Economics, 39(3), 1-64. https:// doi.org/10.1016/j.jacceco.2005.04.005

Saputra, A. R., \& Kesumaningrum, N. D. (2017). Analisis Faktor - Faktor Yang 
Mempengaruhi Fraudulent Financial Reporting Dengan Perspektif Fraud Pentagon Pada Perusahaan Perbankan Yang Terdaftar Di Bursa Efek Indonesia Tahun 2011-2015. Jurnal Akuntansi Dan Keuangan, 22(2), 121-134.

Sari, S. P., \& Nugroho, N. K. (2020). Financial Statements Fraud dengan Pendekatan Vousinas Fraud Hexagon Model: Tinjauan pada Perusahaan Terbuka di Indonesia. 1st Annual Conference of Ihtifaz.

Sari, T. P., \& Lestari, D. I. T. (2020). Analisis Faktor Risiko Yang Mempengaruhi Financial Statement Fraud: Prespektif Diamond Fraud Theory. Jurnal Akuntansi Dan Pajak, 4(2), 109-125. https:// doi.org/10.29040/jap.v20i2.618

Saria, Y. P., Hetika, \& Aryanto. (2019). Metode Pendeteksian Fraud di Indonesia : Sebuah Analisis Review. Journal of Applied Accounting and Taxation, 4(2), 241248.

Sasongko, N., \& Wijayantika, S. F. (2019). Faktor Resiko Fraud Terhadap Pelaksanaan Fraudulent Financial Reporting (Berdasarkan Pendekatan Crown's Fraud Pentagon Theory). Riset Akuntansi Dan Keuangan Indonesia, 4(1), 67-76. https:// doi.org/10.23917/ reaksi.v4i1.7809

Septriyani, Y., \& Handayani, D. (2018). Mendeteksi Kecurangan Laporan Keuangan dengan Analisis Fraud Pentagon. Jurnal Akuntansi, Keuangan Dan Bisnis, 11(1), 11-23. http://jurnal.pcr.ac.id

Shaferi, I., \& Handayani, S. R. (2017). Manajemen perbankan dan kinerja keuangan pada sub sektor bank di bursa efek indonesia. Journal \& Proceeding FEB Unsoed, 7(September), 394-399.

Siddiq, F. R., Achyani, F., \& Zulfikar. (2017). Fraud Pentagon Dalam Mendeteksi Financial Statement. Seminar Nasional Dan The 4th Call for Syariah Paper.

Skousen, C. J., Smith, K. R., \& Wright, C. J. (2009). Detecting and predicting financial statement fraud: The effectiveness of the fraud triangle and SAS No. 99. Advances in Financial Economics, 13, 53-81. https://doi.org/10.1108/S1569-3732(2009)0000013005

Skousen, C. J., \& Twedt, B. J. (2009). Fraud score analysis in emerging markets. Cross Cultural Management: An International Journal, 16(3), 301-316. https:/ / doi.org/10.1108/13527600910977373

Sugiyono, P. D. (2019). Metode Penelitian Pendidikan (Kuantitatif, Kualitatif, Kombinasi, R\&d dan Penelitian Pendidikan). Metode Penelitian Pendidikan.

Sunardi, S., \& Amin, M. N. (2018). Fraud detection of financial statement by using fraud diamond perspective. International Journal of Development and Sustainability, 7(2), 878-891.

Suparmini, N. K., Ariyanto, D., \& Wistawan, I. M. A. P. (2020). Pengujian Fraud Diamond Theory Pada Indikasi Financial Statement Fraud Di Indonesia. EJurnal Akuntansi, 30(6), 1441-1457. https:/ / doi.org/10.24843/EJA.2020.v30.i06.p08

Tessa, C. (2016). Fraudulent Financial Reporting Pengujian Teori Fraud Pentagon pada Sektor Keuangan dan Perbankan di Indonesia. Simposium Nasional Akuntansi.

Ulfah, M., Nuraina, E., \& Wijaya, A. L. (2017). Pengaruh Fraud Pentagon dalam Mendeteksi Fraudulent Financial Reporting (Studi Empiris pada Perbankan di Indonesia yang Terdaftar di BEI). Paper Dipresentasikan Di Forum Ilmiah Pendidikan Akuntansi. 
Utami, E. R., \& Pusparini, N. O. (2019). The Analysis Of Fraud Pentagon Theory And Financial Distress For Detecting Fraudulent Financial Reporting In Banking Sector In Indonesia (Empirical Study Of Listed Banking Companies On Indonesia Stock Exchange In 2012-2017). 5th International Conference of Accounting and Finance, 60-65. https://doi.org/10.2991/icaf-19.2019.10

Widarti, W. (2015). Pengaruh Fraud Triangle Terhadap Deteksi Kecurangan Laporan Keuangan Pada Perusahaan Manufaktur Yang Terdaftar Di Bursa Efek Indonesia (BEI). Jurnal Manajemen Dan Bisnis Sriwijaya. https://doi.org/10.29259/jmbs.v13i2.3351

Wolfe, D. T., \& Hermanson, D. R. (2004). The Fraud Diamond: Considering the Four Elements of Fraud. CPA Journal.

Yulianti, Y., Pratami, S. R., Widowati, Y. S., \& Prapti, L. (2019). Influence of fraud pentagon toward fraudulent financial reporting in Indonesia an empirical study on financial sector listed in Indonesian stock exchange. International Journal of Scientific and Technology Research, 8(8), 237-242.

Zaki, N. M. (2017). The Approriateness Of Fraud Triangle And Diamond Models In Assessing The Likelihood Of Fraudulent Financial Statements-An Empirical Study on Firms Listed In The Egytian Stock Exchange. International Journal of Social Science and Economic Reasearc, 2(2), 2403-2433. 